\title{
Effect of Palm Wine on Reproductive Functions in Male Albino Rats
}

\author{
Oyedeji K.O ${ }^{1}$., Bolarinwa A.F ${ }^{2}$, Hamzat M.A. ${ }^{1}$ \\ ${ }^{l}$ Department of Physiology, Faculty of Basic Medical Sciences, Ladoke Akintola University of Technology, \\ P.M.B. 4000, Ogbomoso, Nigeria. \\ ${ }^{2}$ Department of Physiology, College of Medicine, University of Ibadan, Ibadan, Nigeria.
}

\begin{abstract}
Summary: Palm wine is the sap of a monocarpic crop, Rafia rafia, which is widely grown along the coast of West and Central Africa. Several studies have been reported on the effects of palm wine on fetal cerebral cortex, but due to scanty information on its effects on androgenical studies, reproduction. These studies were designed to investigate the effects of palm wine on testosterone levels and reproductive parameters in Wistar albino rats. Fresh 50\% diluted palm wine was administered orally for 30 days for reproductive studies at the dose of 10 $\mathrm{mL} / \mathrm{kg}$ BW. Distilled water $(0.5 \mathrm{~mL})$ served as control. Testosterone level was assayed using ELISA, semen analysis were done microscopically. Histological analysis of the testis, kidney and liver were also done. Data were analysed using Students' $t$-test at $p<0.05$.

Treatment of rats with palm wine $(10 \mathrm{~mL} / \mathrm{kg} B W)$ caused no significant $(p>0.05)$ increase in body weights of treated rats relative to control. Palm wine $(10 \mathrm{~mL} / \mathrm{kg} \mathrm{BW})$ caused significant decrease in testosterone level $(0.12 \pm 0.02 \mathrm{ng} / \mathrm{ml}$; relative to control $1.38 \pm 0.52 \mathrm{ng} / \mathrm{mL})$. Palm wine $(10 \mathrm{~mL} / \mathrm{kg} \mathrm{BW})$ caused significant decrease in sperm counts, motility and viability, but no significant change in morphology. There were interstistial congestion and odema of the testes. These findings probably indicate that palm wine caused deleterious effects on the reproductive parameters in male albino rats.
\end{abstract}

Key words: Palm wine, Testosterone, Albino rats, Sperm count.

\section{Introduction}

Palm wine also known as palm toddy or simply toddy is a milky alcoholic beverage obtained from the sap of the tropical plants of the Palmae family. It is commonly called "Emu" by the Yoruba ethnic group of Nigria, "Nsafufuo" by the Ghanians and "Tuba" by the Mexicans.

It is widely consumed at homes, in social events, and during performance of some traditional rites. It is also a component of various herbal remedies. It has been reported that fermented palm wine exposure could cause prenatal osteo-inhibitory effects on bones (Eluwa et al., 2010). Palme wine yeasts have also been used for industrial processes like baking and portable ethanol production.

However, due to paucity of information from literature on the effect of palm wine on reproductive parameters in male albino rats, this study therefore aims at investigating the effect of palm wine on these reproductive parameters.

\section{Experimental Animals.}

\section{Materials And Methods}

Adult male albino rats weighing between $160 \mathrm{~g}$ and $180 \mathrm{~g}$ bred in the Animal House of Physiology Department, LAUTECH, Ogbomoso were used. They were housed under standard laboratory conditions with a 12 hours daylight cycle and had free access to feed and water; they were acclimatized to laboratory conditions for two weeks before the commencement of the experiments. All experiments were carried out in compliance with the recommendations of Helsinki's declaration on guiding principles on care and use of animals.

\section{Palm Wine}

Fresh 50\% diluted palm wine obtained from Raffia palm was collected on daily basis from a local palm wine seller in Ogbomoso, Nigeria. The palm wine was administered to the rats according to their body weight using the standard value of $10 \mathrm{ml} / \mathrm{kg} \mathrm{BW}$.

\section{Experimental Design}

Fourteen animals were randomly divided into two groups with each group consisting of seven rats. The two groups of rats were subjected to the following oral treatments once a day for 30 days:

Group I rats received $10 \mathrm{ml} / \mathrm{kg}$ BW of palm wine

Group II rats received $0.5 \mathrm{ml}$ of distilled water as the control group. 
Twenty-four hours (day 31) after the last dosing of the two groups, blood samples were collected and the animals were then euthenised by cervical dislocation for semen analysis. Histological preparation of the testes was also carried out.

Body Weight

Body weight of each rat was monitored on weekly basis.

\title{
Collection of Blood Sample
}

Blood samples were collected through the medial cantus into EDTA bottles for hormonal assay.

\section{Hormonal Assay}

Plasma samples were assayed for testosterone using the enzyme-linked immunosorbent assay (ELISA) technique using the Randox kit.

\section{Semen Collection}

The testes were removed along with the epididymides. The caudal epididymides were separated from the testes, blotted with filter papers and lacerated to collect the semen.

\begin{abstract}
Semen Analysis
Progressive sperm motility: This was done immediately after the semen collection. Semen was squeezed from the caudal epididymis onto a pre-warmed microscope slide $\left(27^{\circ} \mathrm{C}\right)$ and two drops of warm $2.9 \%$ sodium citrate was added, the slide was then covered with a warm cover slip and examined under the microscope using X400 magnification. Ten fields of the microscope were randomly selected and the sperm motility of 10 sperms was assessed on each field. Therefore, the motility of 100 sperms was assessed randomly. Sperms were labelled as motile, sluggish, or immotile. The percentage of motile sperms was defined as the number of motile sperms divided by the total number of counted sperms (i.e. 100) (Mohammad-Reza et al., 2005).
\end{abstract}

Sperm viability (Life/dead ratio): This was done by adding two drops of warm Eosin/Nigrosin stain to the semen on a pre-warmed slide, a uniform smear was then made and dried with air; the stained slide was immediately examined under the microscope using x400 magnification. The live sperm cells were unstained while the dead sperm cells absorbed the stain. The stained and unstained sperm were counted and the percentage was calculated (Laing, 1979).

Sperm morphology: This was done by adding two drops of warm Walls and Ewas stain (Eosin/Nigrosin stain can also be used) to the semen on a prewarmed slide, a uniform smear was then made and air-dried; the stained slide was immediately examined under the microscope using x400 magnification (Laing, 1979). Five fields of the microscope were randomly selected and the types and number of abnormal spermatozoa were evaluated from the total number of spermatozoa in the five fields; the number of abnormal spermatozoa were expressed as a percentage of the total number of spermatozoa.

Sperm count: This was done by removing the caudal epididymis from the right testes and blotted with filter paper. The caudal epididymis was immersed in $5 \mathrm{ml}$ formol-saline in a graduated test-tube and the volume of fluid displaced was taken as the volume of the epididymis. The caudal epididymis and the $5 \mathrm{ml}$ formol-salline were then poured into a mortar and homogenized into a suspension from which the sperm count was carried out using the improved Neubauer haemocytometer under the microscope.

\section{Testicular Histology}

After weighing the testes, they were immediately fixed in Bouin's fluid for 12 hours and the Bouin's fixative was washed from the samples with $70 \%$ alcohol. The tissues were then cut in slabs of about $0.5 \mathrm{~cm}$ transversely and the tissues were dehydrated by passing through different grades of alcohol: $70 \%$ alcohol for 2 hours, 95\% alcohol for 2 hours, 100\% alcohol for 2 hours, 100\% alcohol for 2 hours and finally $100 \%$ alcohol for 2 hours. The tissues were then cleared to remove the alcohol; the clearing was done for 6 hours using xylene. The tissues were then infilterated in molten Paraffin wax for 2 hours in an oven at $57^{\circ} \mathrm{C}$, thereafter the tissues were embedded. Serial sections were cut using rotary microtone at 5 microns $(5 \mu \mathrm{m})$. The satisfactory ribbons were picked up from a water bath $\left(50^{\circ}-55^{\circ} \mathrm{C}\right)$ with microscope slides that had been coated on one side with egg albumin as an adhesive and the slides were dried in an oven. Each section was deparaffinized in xylene for 1 minute before immersed in absolute alcohol for 1 minute and later in descending grades of alcohol for about 30 seconds each to hydrate it. The slides were then rinsed in water and immersed in alcoholic solution of hematoxylin for about 18 minutes. The slides were rinsed in water, then differentiated in $1 \%$ acid alcohol and 
then put inside a running tapwater to blue and then counterstained in alcoholic eosin for 30 seconds and rinsed in water for a few seconds, before being immersed in 70\%, $90 \%$ and twice in absolute alcohol for 30 seconds each to dehydrate the preparations. The preparations were cleared of alcohol by dipping them in xylene for 1 minute. Each slide was then cleaned, blotted and mounted with DPX and cover slip, and examined under the microscope. Photomicrographs were taken at x40, x100 and x400 magnifications

\section{Statistical Analysis}

The mean and standard error of mean (S.E.M.) were calculated for all values. Comparisons between the control and the treated groups were done using the student's t-test. Differences were considered statistically significant at $\mathrm{p}<0.05$.

\section{Results}

Treatment of rats for 30 days with $10 \mathrm{ml} / \mathrm{kg}$ BW of palm wine caused non-significant $(\mathrm{p}>0.05)$ changes in body weight relative to the control.

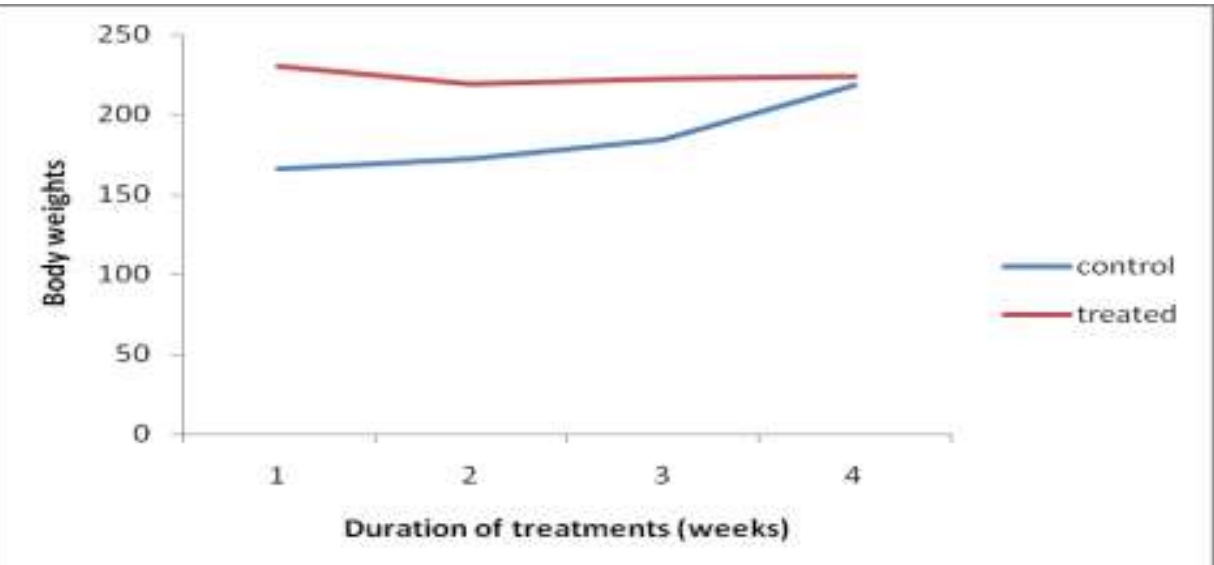

Figure 1:Effect of 30 days treatment of rats with palm wine $(10 \mathrm{ml} / \mathrm{kg} \mathrm{BW})$ on body weight of male albino rats $\left(\mathrm{n}=7,{ }^{*} \mathrm{p}<0.05\right)$.

\section{Effect on Hormonal Levels}

Treatment of rats for 30 days with palm wine $(10 \mathrm{ml} / \mathrm{kg} \mathrm{WB})$ caused significant $(\mathrm{p}<0.05)$ decrease in testosterone levels relative to the control.

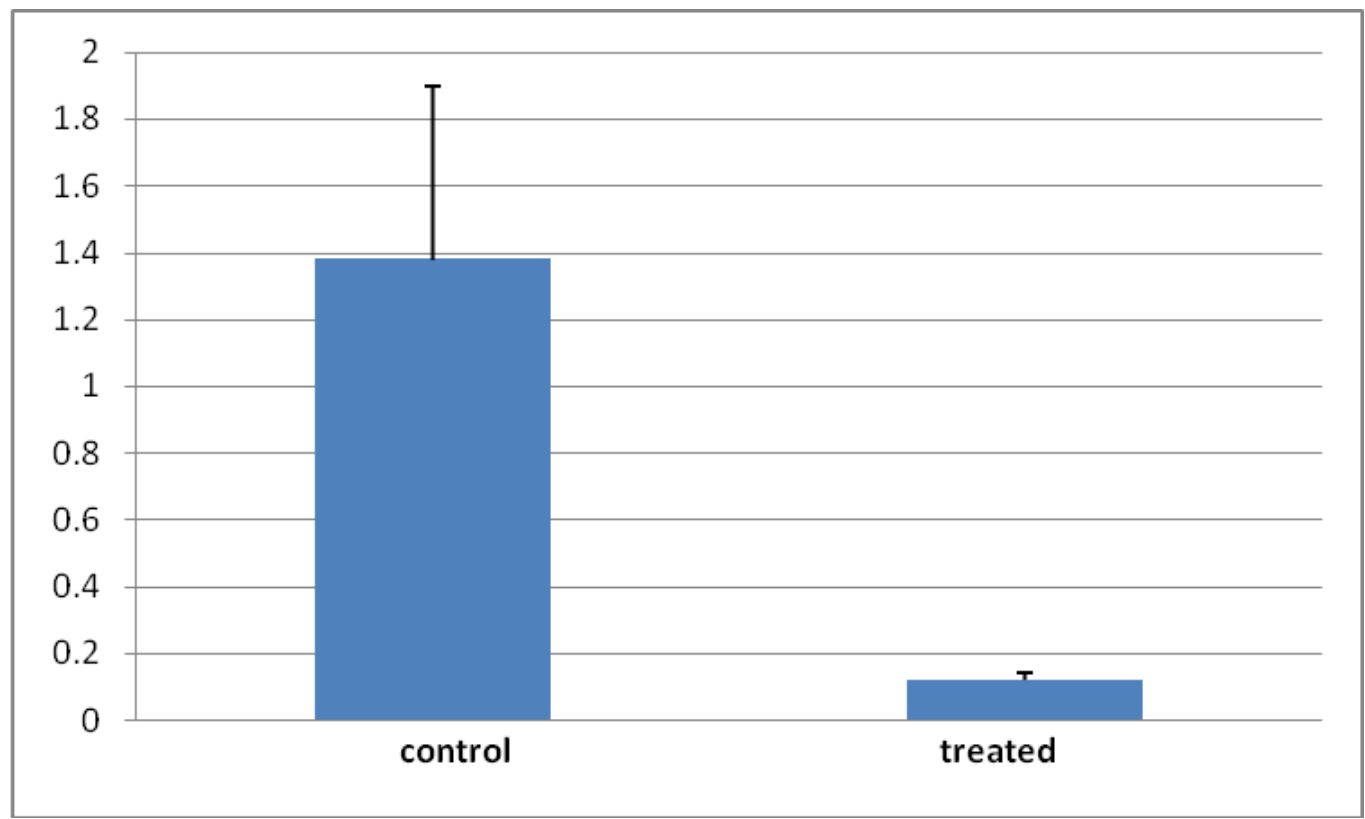

\section{Groups}

Figure 2: Effect of 30 days (4 weeks) treatment with palm wine on testosterone levels of male rats $(n=7$, $* p>0.05)$. 


\section{Effect on sperm Characteristics}

Treatment of rats for 30 days with palm wine $(10 \mathrm{ml} / \mathrm{kg} \mathrm{BW})$ caused significant $(\mathrm{p}<0.05)$ decrease in sperm motility relative to the control. Palm wine $(10 \mathrm{ml} / \mathrm{kg} \mathrm{BW})$ caused significant $(\mathrm{p}<0.05)$ decrease in sperm viability (life/dead) as well as significant $(\mathrm{p}<0.05)$ increase in the percentage of abnormal sperm cells. It also caused significant $(\mathrm{p}<0.05)$ decrease in sperm count.

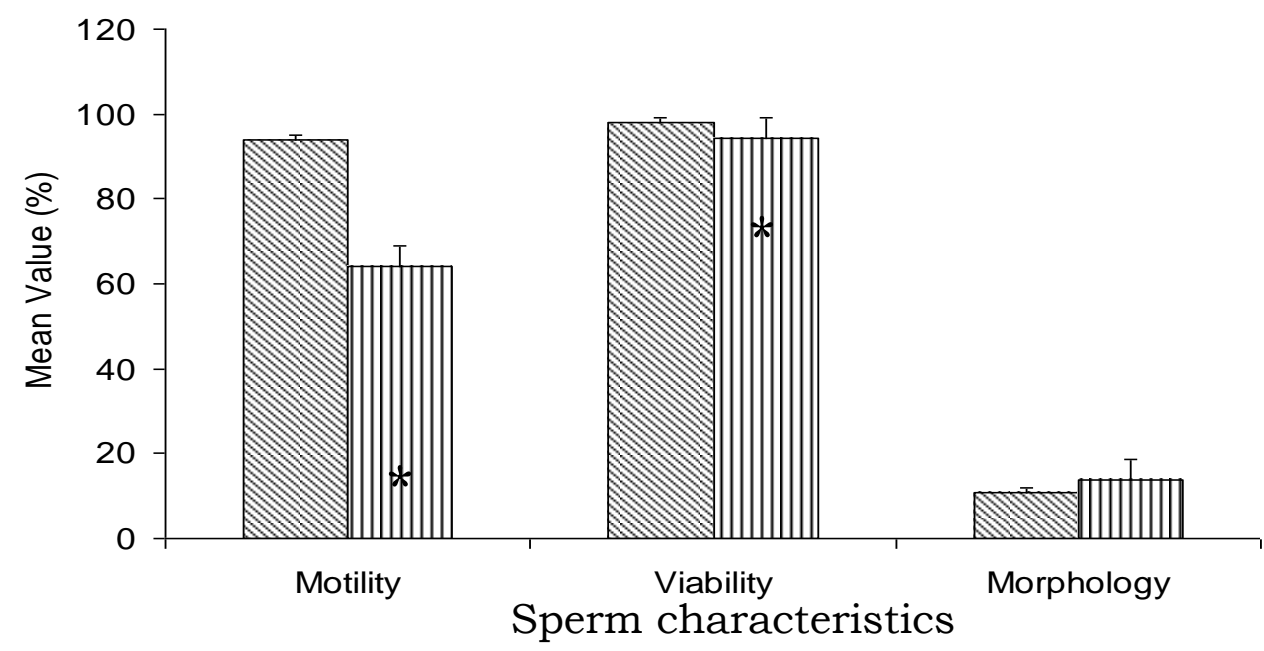

Figure 3: Spermogram showing the effect of 30 days treatment with palm wine $(10 \mathrm{ml} / \mathrm{kg} \mathrm{BW})$ on sperm characteristics $\left(\mathrm{n}=7,{ }^{*} \mathrm{p}<0.05\right)$.

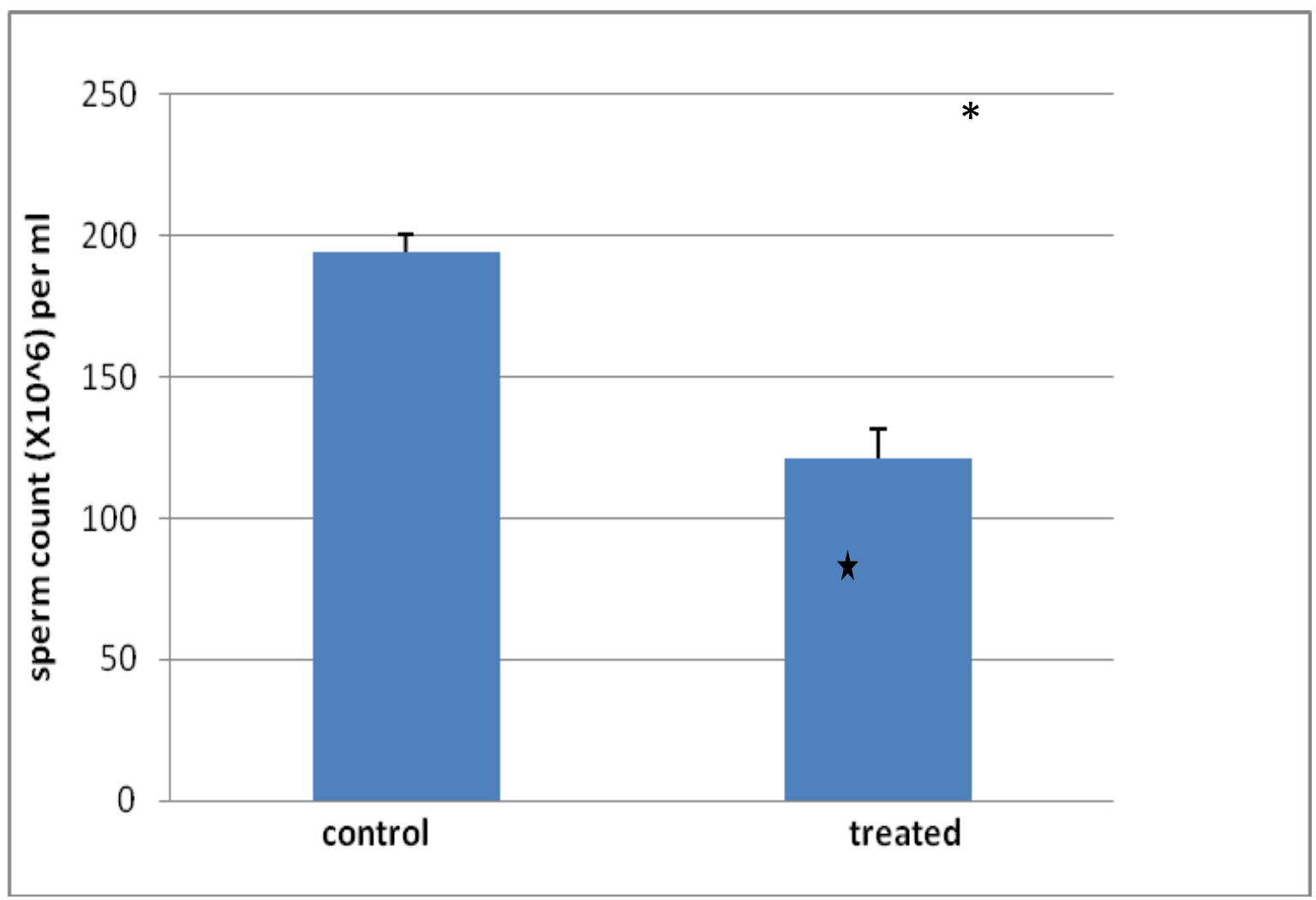

Groups

Figure 4: Spermogram showing the effect of 30 days treatment with palm wine $(10 \mathrm{~mL} / \mathrm{kg} \mathrm{BW})$ on sperm count $(\mathrm{n}=7, * \mathrm{p}<0.05)$.

\section{Histopathological Findings}

Treatment of rats for 30 days with palm wine $(10 \mathrm{ml} / \mathrm{kg} \mathrm{BW})$ caused mild interstitial congestion and oedema but normal germinal epithelium; however, the control presented with normal interstitium. 


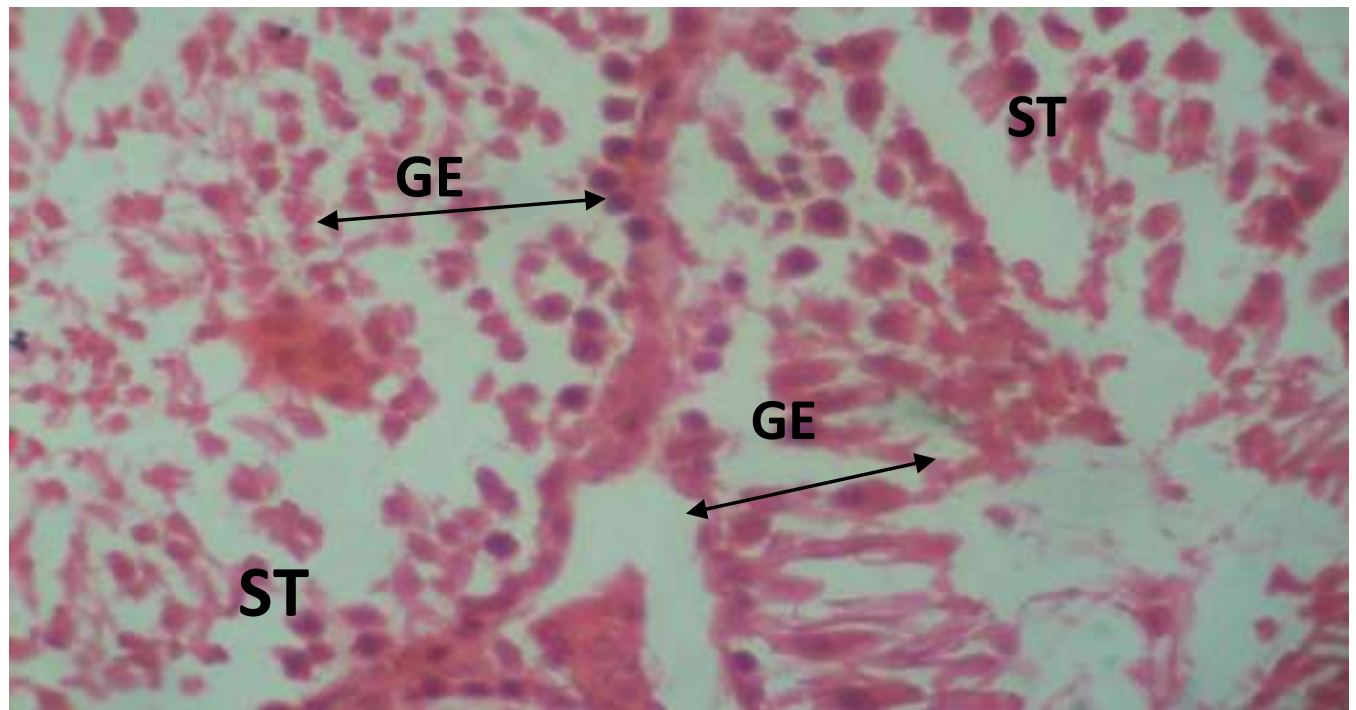

Plate 1: The effect of $0.5 \mathrm{~mL}$ of distilled water (control) on testes after treatment of rats for 30 days (X400).

Photomicrograph showing normal vaible germinal epthilium (GE). No visbile lesions observed at the interstitium (I) and the seminiferous tubules (ST).

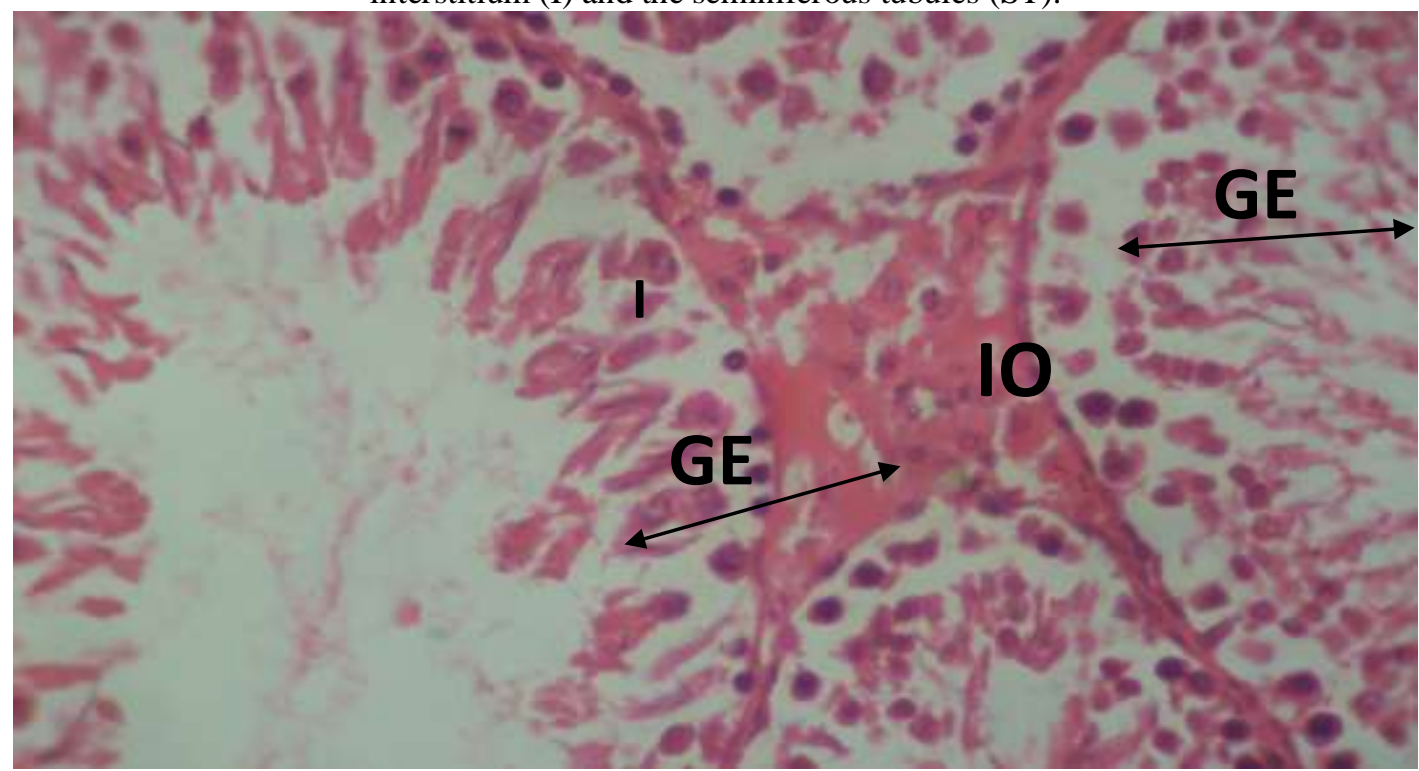

Plate 2: The effect of $10 \mathrm{~mL} / \mathrm{kg} \mathrm{BW}$ of palm wine on the testes after treatment of rats for 30 days (X400). Photomicrograph showing normal viable germinal epithilium (GE) with mild interstitium odema (IO).

\section{Discussion}

Palm wine caused non-significant changes in body weight of rats after treatment for 30 days, this suggests that palm wine was not toxic to the animals as well as non-androgenic in nature, since androgens are known to possess anabolic activities. Similar report was given by Gonzales et al., (2006) in rats treated with Lepidium meyenii extreacts.

Palm wine caused significant decrease in testosterone levels. Similar report was given by Das et al. (2009) in rats treated with Aegle mermelos extract. This decrease in testosterone levels could indicate that palm wine inhibits the mechanism intervening in the process of hormone synthesis in the Leydig cells.

The andrological results show that treatment of rats for 30 days with palm wine caused significant decrease in sperm motility. Similar report was given by Verma et al. (2002) in rats treated with Sarcostemma acidum extract. This suggests that palm wine was able to permeate the blood-testis barrier with a resultant alteration in the microenvironment of the seminiferous tubules, since it has been reported that the decrease in sperm motility caused by chemical agents was due to their ability to permeate the blood-testis barrier (Baldessarini, 1980) and thus, creating a different microenvironment in the inner part of the wall of the seminiferous tubules from that in the outer part (Bloom and Fawcett, 1975).

Palm wine caused significant decrease in sperm viability as well as significant increase in the percentage of morphological abnormal sperm cells in the treated rats. This could be due to the ability of palm 
wine to either interfere with the spermatogenic processes in the seminiferous tubules, epididymal functions or activities of testosterone on hypothalamic release factor and anterior pituitary secrtion of gonadotropins which may result in alteration of spermatogenesis (William, 2000; Bowman and Rand, 1985).

Palm wine caused significant decrease in sperm count of the treated rats which could be as a result of decrease in plasma levels of testosterone since this hormone has been reported to be important in the initiation and maintenance of spermatogenesis (Christensen, 1975). Similar report was given by Krishnamoorthy et al. (2007) in Terminalia chebula extract treated rats

Treatment of rats with palm wine caused mild interstitial congestion and oedema. Similar results were respectively reported by Manna et al. (2005) as well as Mohammed and Ameen (2007) in rats treated with deltamethrin and sumithion. These could be due to (i) increased hydrostatic pressure (ii) reduced oncotic pressure (iii) lymphatic obstruction or (iv) sodium retention (Kumar et al., 1999).

\section{References}

[1] Baldessarini RJ (1980): In drugs and the treatment of psychiatriod disorders. The pharmacological basis of therapeutics Ed. By Goodman and Gilman. Macmillan Pub. Co. Inc. pp. 301-417.

[2] Bloom W, Fawcett DW (1975): Male reproductive system. In the textbook of Histology. Saunders Company, Philadelphia.

[3] Bowman WC, Rand MJ (1985): The reproductive system and drugs affecting the reproductive systems. Textbook of pharmacology, 2nd edition, 20:1-8.

[4] Christensen AC (1975): Leydig cell: In: Handbook of Physiology, edited by P.O. Greep and E.B. Astwoods. Washington D C American Physiological Society.

[5] Das UK, De D, Chatterjee K, Mallick C, Bera TK, Ghosh D (2009): Antigonadal effect induced by hydro-methanolic extract of leaf of Aelgle mermelos in male rat: Effect of hCG co-administration. Journal of Medicinal Plants Research Vol. 3(10), Pp728 - 735.

[6] Eluwa MA, Agarrey LE, Ekanem TB, Amabe OA, Agnes OE, Ekong MB (2010): Comparative study of teratogenic effects of brewed beer and palm wine on fetal femur bone of albino Wistar rats. Int. J. Biomed. And Health Sci. Vol., 6, No 4 pp $229-233$.

[7] Gonzales C, Rubio J, Gasco M, Nieto J, Sandra Y, Gonzales GF (2006): Effect of short-term and long-term treatments with three ecotypes of Lepidium meyenii (MACA) on spermatogenesis in rats. Journal of Ethnnopharmacol. (103), 448 - 454

[8] Krishnamoorthy P, Viathinathan S, Rani V, Bhuvaneswari A (2007): Effect of Terminalia chebula fruit extract on lipid peroxidation and antioxidative system of testis of albino rats. African Journal of Biotechnology, Vol. 6 (16), Pp 1888 - 1891.

[9] Kumar, Abbas, Fausto (1999): Pathology Bases of Disease, $7^{\text {th }}$ edition, China: Elsevier Saunders, 122.

[10] Laing JA (1979): Fertility and infertility in domestic animals. 3rd edition 1979 Bailliere Tindall, a division of Cassell Lt.

[11] Manna S, Bhattacharrya D, Mandal TK, Das S (2005): Repeated dose toxicity of deltamethrin in rats. India J. Pharmacol 37: 160 164.

[12] Mohammad - Reza P, Farzaneh D, Taherch TK, Zoherb PP (2005): The effects of hydroalcholic extract of Actinidia chinensis on sperm count and motility, and blood levels of estradiol and testosterone in male rats. Achieves of Iranina Medicine, Volume 8, Number 3, 211-216

[13] Mohammed OA, Ameen SBB (2007): Testicular histopathological alterations in rats treated with sumithion* NP 25/2.5 EC, insecticide. J. Biol. Sci 7(3): $520-525$

[14] Verma PK, Sharma A, Annu M, Prachi S, Gupta RS, Joshi SC, Dixit VP (2002): Effect of Sarcostemma acidum stem extract on spermatogenesis in male albino rats. J. Androl. 4(1): $43-47$.

[15] William KW (2000): Hormones and Hormone antagonists. In: Remington, The Science and Practise of Pharmacy, vol 11, 20th edition 77: 1390-1391. 